\title{
Poem
}

\section{You float on a raft of morphine}

The news is particularly bad when the doctor reaches into the black bag and pulls out a metaphor. But when she compares aneurysm to overinflated innertube, I think of a lazy summer trip on the Gunpowder legs dangling instream. Not bloodstream.

Hooked and coiled and tethered, you float on a raft of morphine while your life is measured in primer-book sentences your son is barely old enough to read:

Heather can open her eyes.

Heather can squeeze her left hand.

Heather can blink.

Let me free you from all this and take you to the river. Never mind that it's December, and Winter has spread her threadbare blanket of ice. There on the banks, do you see the curled fists of fiddleheads? 